\title{
On call: a valuable training experience for senior house officers?
}

\section{AIMS AND METHOD}

To describe the experiences of psychiatric senior house officers (SHOs) of being on call. A survey of SHOs on three on-call rotas across south Birmingham was conducted to investigate their opinions about on-call work and to consider how time on call is spent.

\author{
RESULTS \\ SHOs in psychiatry gain a broad range \\ of experience out of hours on a tra- \\ ditional on-call rota. On-call periods \\ were valued as a learning experience \\ and $63 \%$ of SHOs were confident in \\ their decision-making while on call. \\ However, on-call work was often \\ viewed as isolating, and not all SHOs \\ felt that they were working as part of \\ a team when on call.
}

\begin{abstract}
CLINICAL IMPLICATIONS
As changes to working patterns are introduced, for example in order to implement the European Working Time Directive, care must be taken to retain the positive aspects of current on-call systems. Such changes should be seen as an opportunity to improve working lives so that SHOs feel less isolated when providing out-ofhours cover.
\end{abstract}

Senior house officers (SHOs) spend a significant proportion of their working hours on call, yet there is little published information describing what they actually do on call. Searches of EMBASE (1980-2003), Medline (1966-2003) and PsycLIT (1887-2003) undertaken using the keywords SENIOR HOUSE OFFICERS, TRAINING and ON-CALL found only four papers (Baldwin et al, 1997; Paice et al, 1997; Hurley \& Paterson-Brown, 1999; Brown et al, 2002) which were descriptive studies of what medical and surgical SHOs spend their time doing while on call and a survey of SHOs' perception of training across all specialties. No study looking specifically at the experiences of SHOs in psychiatry was found.

Senior house officer posts are training posts and there may be conflict between training SHOs and delivering service, with 'service-based training' being proposed as the most viable solution. This is arguably most easily achievable during conventional working hours when the SHO's work can be overseen and workload manipulated by others on the team to ensure that training needs are being met. Although SHOs have been described as representing cheap labour to the National Health Service (NHS) and as being particularly valuable for out-of-hours emergency work (Harris \& Ferreira, 1997), on-call work may offer a unique training opportunity.

The Royal College of Psychiatrists offers little guidance as to what experience psychiatric trainees should expect, and be expected, to gain on call. There is only one relevant sentence in the College's Basic Specialist Training Handbook stating: 'trainees must have experience in participating in a first on call rota with a minimum of 55 nights on call during the period of basic specialist training' (Royal College of Psychiatrists, 2003, para. 2.7) No advice is offered on what a first on-call rota should involve.

As of 1 August 2004 junior doctors in the NHS are no longer excluded from the provisions of the European Working Time Directive. This limits their working hours first to 58 hours a week, and by 2009 to 48 hours a week. This will inevitably lead to the introduction of shift working in place of more traditional on-call rotas and is likely to affect the training of SHOs.

We wanted to see what SHOs' experiences of psychiatric on-call work were and what particular concerns trainees might have regarding being on call. We also wanted to directly ask SHOs for their thoughts on the proposed changes to on-call working patterns that will be introduced in order to implement the Working Time Directive.

\section{Method}

The authors used the College document Learning Objectives for SHOs (Royal College of Psychiatrists, 2002) to inform the design of two questionnaires.

The first questionnaire was in three parts. Respondents were asked to indicate how strongly they agreed with 15 statements about on-call working on a five-point Likert rating scale (Table 1). They were asked to give a yes/no response to two statements - whether or not changing to a shift system would offer benefits to their personal life, and whether or not it would offer better training opportunities. They were also asked to give examples of tasks that they had been asked to do on-call that they considered to have been inappropriate, and were given the opportunity to make any other comments about on-call work.

The second questionnaire sought information about tasks during specific on-call periods. Respondents were asked to detail the number of assessments, admissions and risk assessments carried out and to provide brief details about these (Table 2). They were also asked about any management plans they had devised during the oncall period. Information was sought on whether SHOs discussed issues with, or sought advice from, senior medical staff or other colleagues during the on-call period and whether or not they would discuss any aspects of that on-call period during supervision.

Senior house officers covering three psychiatry oncall rotas across south Birmingham were invited to 
Table 1. Senior house officers' opinions about on-call work $(n=24)$

original papers

\begin{tabular}{|c|c|c|c|c|c|c|}
\hline & $\begin{array}{c}\text { Strongly } \\
\text { disagree } \\
(\%)\end{array}$ & $\begin{array}{l}\text { Disagree } \\
(\%)\end{array}$ & $\begin{array}{l}\text { Undecided } \\
\qquad(\%)\end{array}$ & $\begin{array}{l}\text { Agree } \\
(\%)\end{array}$ & $\begin{array}{l}\text { Strongly } \\
\text { agree } \\
(\%)\end{array}$ & $\begin{array}{l}\text { No } \\
\text { answer } \\
(\%)\end{array}$ \\
\hline On-calls are an important part of training & 0 & 4 & 0 & 54 & 10 & 0 \\
\hline On-calls are an important part of service provision & 0 & 0 & 0 & 63 & 38 & 0 \\
\hline On-calls are isolating & 0 & 21 & 33 & 29 & 17 & 0 \\
\hline $\begin{array}{l}\text { Supervision is a good opportunity to discuss difficulties } \\
\text { encountered on call }\end{array}$ & 0 & 21 & 0 & 54 & 25 & 0 \\
\hline I have an on-going commitment to patients seen on-call & 0 & 33 & 21 & 33 & 8 & 4 \\
\hline On-calls offer important learning experiences & 0 & 0 & 4 & 58 & 37 & 0 \\
\hline I know who to contact for advice when I am on call & 0 & 4 & 0 & 75 & 21 & 0 \\
\hline I am confident in my decision making when I am on call & 0 & 8 & 29 & 54 & 8 & 0 \\
\hline $\begin{array}{l}\text { On-call experience is different to that gained during } \\
\text { conventional working hours }\end{array}$ & 0 & 4 & 0 & 63 & 21 & 12 \\
\hline $\begin{array}{l}\text { I am reluctant to contact senior colleagues when I am } \\
\text { on call }\end{array}$ & 17 & 54 & 12 & 17 & 0 & 0 \\
\hline I manage my time efficiently when I am on call & 8 & 4 & 17 & 66 & 4 & 0 \\
\hline On-call experience is important for the MRCPsych exam & 4 & 8 & 33 & 42 & 12 & 0 \\
\hline I am working as part of a team when I am on call & 4 & 8 & 33 & 42 & 12 & 0 \\
\hline I am asked to do inappropriate tasks when I am on call & 0 & 21 & 33 & 33 & 12 & 0 \\
\hline Senior colleagues do not want to be contacted on call & 8 & 58 & 17 & 17 & 0 & 0 \\
\hline
\end{tabular}

participate in the study. These were resident on-call SHOs, covering general practitioner referrals and the wards, and non-resident on-call SHOs, covering accident and emergency and liaison referrals, at a teaching hospital and $\mathrm{SHO}$ on-call at a district general hospital. A brief outline of the study was presented to the SHOs at their respective academic meetings prior to the start of the study period. All SHOs were asked to complete the first questionnaire at the outset of the study. They were asked to complete a second questionnaire for each $24 \mathrm{~h}$ on-call period during the study period, which lasted 85 days. Questionnaires were left in the on-call rooms for resident on-call SHOs and in the doctors' mess for non-resident on-call SHOs. Telephone prompts at the end of the on-call period were undertaken to remind SHOs to complete the questionnaires.

\section{Results}

The first questionnaire was returned by 24 of the 32 SHOs, an overall response rate of $75 \%$. The second questionnaire was completed for 207 on-call periods, an overall response rate of $81.2 \%$.

\section{Opinions}

Senior house officers often felt that they were asked to undertake inappropriate tasks when on call (Table 1). These tasks fell broadly into four categories: inappropriate referrals ('assessing drunk people in $A \& E^{\prime}$ ); tasks that should have been completed by others during conventional working hours; non-urgent medical problems ('5 years' worth of knee pain needed review on Bank Holiday Monday'); and administrative tasks such as finding beds and arranging patient transfers.

Table 2. Tasks carried out by senior house officers on call

\begin{tabular}{|c|c|c|}
\hline \multirow[b]{2}{*}{ On-call task } & \multicolumn{2}{|c|}{ Number } \\
\hline & Mean & Range \\
\hline Admissions & 1.08 & $0-7$ \\
\hline Formal admissions & 0.44 & $0-6$ \\
\hline Risk assessments & 1.98 & $0-10$ \\
\hline Risk assessments discussed with a senior colleague & 0.35 & $0-4$ \\
\hline Risk assessments discussed with ward staff & 1.07 & $0-5$ \\
\hline Management plans & 1.95 & $0-19$ \\
\hline Management plans discussed with senior colleagues & 0.47 & $0-7$ \\
\hline
\end{tabular}


There were concerns about proposals to change working patterns from the traditional on-call system to a shift system. Seven trainees (29\%) felt that changing to a shift system would offer benefits to their personal life; 15 (63\%) did not. Seven trainees (29\%) felt that shift working would offer better training opportunities; 16 $(67 \%)$ did not.

\section{Tasks}

Table 2 outlines the tasks undertaken by the SHOs during a $24 \mathrm{~h}$ on-call period. Advice was sought from senior colleagues during 70 (34\%) on-call periods. Respondents stated that there were issues relating to $84(41 \%)$ of the on-call periods that they would discuss in supervision.

\section{Discussion}

This survey suggests that trainees in psychiatry gain a broad range of experience out-of-hours on a traditional on-call rota with responsibility for assessing and admitting patients, making risk assessments and devising management plans. In general, on-call periods were valued as a learning experience, and experience gained on-call was considered to be different from that gained during conventional working hours. Respondents were fairly confident in their decision-making and their ability to manage their time when on call.

Trainees in all medical specialties have expressed concern about whether they can be satisfactorily trained under the European Working Time Directive (Pickersgill, 2001) with conflict between the intensity of work undertaken and gaining adequate experience. The shift systems, which will inevitably be introduced in order to implement the Directive, were viewed with suspicion by SHOs in this study, with only a minority considering that it would offer benefits to either their personal lives or their training. Comments were made that SHOs 'strongly feel that changing to partial shift will be detrimental to training and patient care' and that 'change to a shift system is likely to have significant effects on personal life and also be disruptive to 9-5 duties'.

There is no doubt that being on call on a traditional rota system, and in particular being sleep-deprived when working the following day, is also disruptive to $9-5$ duties and to training and has implications for both staff and patient safety. Provision of a safe working environment has been an important factor driving the implementation of the Working Time Directive and should be welcomed, but in introducing changes, it will be important not to lose sight of those aspects of on-call duty that work well at present and are valued by trainees in offering important learning experiences. In particular, trainees were positive about the different types of experience that on-call work offered, and seemed confident about their abilities to make decisions. As might be expected the main tasks were assessments, in particular risk assessments, which the trainees were usually able to carry out without discussion with a senior.
In psychiatry SHOs are very much on the 'front line' while on call and are working with seniors who are usually off-site, and it is recognised that acute on-call work can be very stressful (Guthrie et al, 1999). Educational supervision can minimise job stress (Guthrie et al, 1999) and the respondents to our survey recognised this and valued supervision. Perhaps unsurprisingly, many SHOs viewed on-call work as isolating. In this study trainees said that they knew whom to contact to seek advice and said that they were happy to contact seniors and discuss issues with the ward staff. However, there was a noticeable discrepancy between the number of management plans devised by, and risk assessments carried out by, SHOs and those discussed with senior colleagues or ward staff. This is concerning, as a risk assessment undertaken out of hours is meaningless and potentially dangerous if carried out in isolation. Some SHOs in our study said that they did not feel that they worked as part of a team when on call, but this might at least partly be because they did not avail themselves of the opportunity to liaise with medical and nursing colleagues, despite saying that they were happy to do so. Teamwork is viewed as essential in psychiatry, and it is important that as work patterns are about to change SHOs continue to have a role as members of the multidisciplinary team around the clock. The challenge will be to ensure that SHOs feel less isolated when working on a shift system, not least by encouraging a collaborative approach with their nursing and senior medical colleagues, yet retain the current breadth of experience and responsibility that on-call work seems to provide.

\section{Declaration of interest}

None.

\section{References}

BALDWIN, P. J., NEWTON, R.W. BUCKLEY, G., et al (1997) Senior house officers in medicine: postal survey of training and work experience. BMJ, 314 $740-743$.

BROWN, J., DE COSSART, L. \& WILTSHIRE, C. (2002) Exploring the views of basic surgical trainees (senior house officers) on a basic surgical training scheme. Medical Teaching, 24, 559-561.

GUTHRIE, E., TATTAN, T., WILLIAMS, E., et al (1999) Sources of stress, psychological distress and burnout in psychiatrists. Psychiatric Bulletin, 23, 207-212

HARRIS, E. \& FERREIRA, P. (1997) Training senior house officers. BMJ 314, 692-693.

HURLEY, P. A. \& PATERSON-BROWN, S. (1999) Senior House Officer training: some myths exposed. Journal of the Royal College of Surgeons Edinburgh, 44, 324-327.

PAICE, E., WEST, G., COOPER, R., et al (1997) Senior house officer training: is it getting better? A questionnaire survey. BMJ, 314, 719-720.

PICKERSGILL,T. (2001) The European working time directive for doctors in training. BMJ, 323, 1226.

ROYAL COLLEGE OF PSYCHIATRISTS (2002) Learning Objectives for SHOs. London: Royal College of Psychiatrists.

ROYAL COLLEGE OF PSYCHIATRISTS (2003) Basic Specialist Training Handbook. London: Royal College of Psychiatrists.

*Rhiannon Callaghan Specialist Registrar in Psychiatry, Queen Elizabeth Psychiatric Hospital, Mindelsohn Way, Vincent Drive, Edgbaston, Birmingham B15 2QZ， Gabra Hanna Specialist Registrar in Psychiatry, Queen Elizabeth Psychiatric Hospital, Birmingham, Nick Brown Consultant Psychiatrist, Lyndon Clinic, Solihull, Christopher Vassilas Consultant Psychiatrist, Queen Elizabeth Psychiatric Hospital, Birmingham original papers 